\title{
GAMBARAN POSTUR KERJA DAN RISIKO TERJADINYA MUSKULOSKELETAL PADA PEKERJA BAGIAN WELDING DI AREA WORKSHOP BAY 4.2 PT. ALSTOM POWER ENERGY SYSTEMS INDONESIA
}

\author{
DESCRIPTION OF WORKING POSTURE AND MUSCULOSKELETAL RISK OF \\ WELDING PART WORKERS IN WORKSHOP AREA BAY 4.2 PT. ALSTOM POWER \\ ENERGY SYSTEMS INDONESIA
}

\author{
Rian Yuni Kurnianto \\ Rumah Sakit Umum Daerah Dr. Soetomo, Surabaya, Jawa Timur \\ E-mail: rian.putrablitar@rocketmail.com
}

\begin{abstract}
Worker in welding division is needed in steam boiler industry such as PT. ALSTOM Power Energy Systems Indonesia for combine the steel pipe so it can bond perfectly. Musculoskeletal complaint can necessary happen when they work. Unergonomic work posture, to much force and repeating work can increase the probability of musculoskeletal complaint. The purpose of this research is to detect the work posture that can risk musculoskeletal complaint in welding division worker at workshop bay 4.2 area in PT. ALSTOM Power Energy Systems Indonesia. The research was implemented with descriptive observational approach with cross section method. The research responden are 13 workers in welding division. The data collected at workshop area bay 4.2 area in PT. ALSTOM Power Energy Systems Indonesia. The variabels that researched are individual factors and work factors. The individual factors are age, work duration, smoking habit, and body size (anthropometry). The work factors are work posture and musculoskeletal complaint. The data that had been collected then analyzed with table and narration descriptively. The result founded that workers at the age of 25-30 years old that had been worked for more than 10 years was 46.15\%, 53.85\% had smoking habit, and $61.54 \%$ had BMI overweight preobese category. It can be conclude that eight of thirteen welding workers had stoop back work posture, below shoulder arm position and have a risk to have musculoskeletal system damage. To cope with that, EHS PT. ALSTOM Power Energy Systems Indonesia have to prepare equipment and work station that can be arrange by its needs so it can decrease the gap between worker and work object or make a small chair available so the worker don't have to kneel or stoop.
\end{abstract}

Keywords: work posture, musculoskeletal complaint, welding workers

\begin{abstract}
ABSTRAK
Tenaga kerja bagian welding sangat dibutuhkan dalam industri pembuatan steam boiler di PT. ALSTOM Power Energy Systems Indonesia yaitu untuk menggabungkan pipa baja sehingga terbentuk ikatan yang permanen. Tenaga kerja bagian welding ketika bekerja dapat berisiko mengalami keluhan muskuloskeletal. Postur kerja yang tidak ergonomis, tenaga yang berlebihan dan pengulangan tenaga kerja dapat meningkatkan timbulnya keluhan muskuloskeletal. Tujuan dari penelitian ini adalah untuk mengetahui postur kerja yang berisiko mengalami keluhan muskuloskeletal pada pekerja welding di area workshop Bay 4.2 PT. ALSTOM Power Energy Systems Indonesia. Penelitian dilaksanakan dengan pendekatan observasional deskriptif dengan rancangan cross sectional. Responden penelitian adalah pekerja welding yang berjumlah 13 pekerja. Pengambilan data dilakukan di area workshop Bay 4.2 PT. ALSTOM Power Energy Systems Indonesia. Variabel yang diteliti adalah faktor individu meliputi umur, masa kerja, kebiasaan merokok, dan ukuran tubuh (antropometri). Faktor pekerjaan yaitu postur kerja dan keluhan muskuloskeletal. Data yang telah terkumpul dianalisa dengan tabel dan narasi secara deskriptif. Hasil penelitian didapatkan 46,15\% pekerja berumur 25-35 tahun, 46,15\% telah bekerja selama $>10$ tahun, 53,85\% memiliki kebiasaan merokok, 61,54\% memiliki BMI kategori Overweight Pre-obese. Kesimpulan yang dapat ditarik adalah delapan dari tiga belas total pekerja welding dengan postur kerja posisi punggung membungkuk, posisi lengan di bawah bahu dan duduk berpotensi mengalami kerusakan pada sistem muskuloskeletal. Cara penanggulangan untuk mengurangi kejadian keluhan musculoskeletal adalah pihak HSE PT. ALSTOM Power Energy System Indonesia menyediakan peralatan dan stasiun kerja yang dapat diatur sesuai kebutuhan sehingga memperkecil jarak antara pekerja dengan obyek kerja atau bisa juga menyediakan bangku kecil agar pekerja tidak berlutut atau membungkuk.
\end{abstract}

Kata kunci: postur kerja, keluhan muskuloskeletal, pekerja welding 


\section{PENDAHULUAN}

Kesehatan dan keselamatan kerja merupakan salah satu persyaratan untuk meningkatkan produktivitas kerja tenaga kerja. Selain itu kesehatan dan keselamatan kerja merupakan hal yang sangat penting dalam meningkatkan kesejahteraan dan jaminan sosial para pekerja. Dengan usaha menerapkan keselamatan dan kesehatan kerja maka permasalahan kesehatan kerja dapat dikurangi dan dihindari. Secara umum pencapaian keselamatan dan kesehatan kerja tidak lepas dari peran ergonomi, karena ergonomi berkaitan dengan orang yang bekerja, selain dalam rangka efektivitas dan efisiensi kerja (Sedarmayanti, 1996).

Ergonomi sebagai salah satu bagian dari ilmu kesehatan masyarakat yang berusaha untuk menyerasikan antara faktor manusia, faktor pekerjaan dan faktor lingkungan. Dengan bekerja secara ergonomis maka diperoleh rasa nyaman dalam bekerja, dihindari kelelahan, dihindari gerakan dan upaya yang tidak perlu serta upaya melaksanakan pekerjaan menjadi sekecil-kecilnya dengan hasil yang sebesar-besarnya (Soedirman, 1989).

Salah satu tipe masalah ergonomi yang sering dijumpai khususnya yang berhubungan dengan kekuatan dan ketahanan manusia dalam melakukan pekerjaannya adalah keluhan musculoskeletal disorders (MSDs). Masalah tersebut lazim dialami para pekerja yang melakukan gerakan yang sama berulang secara terus-menerus. Pekerjaan dengan beban yang berat dan perancangan alat yang tidak ergonomis mengakibatkan pengerahan tenaga yang berlebihan dan postur yang salah seperti memutar dengan membungkuk dan membawa beban adalah merupakan risiko terjadinya keluhan muskuloskeletal dan kelelahan dini.

Salah satu penyebab utama gangguan otot rangka adalah postur janggal (awkward posture). Postur janggal adalah posisi tubuh yang menyimpang secara signifikan terhadap posisi normal saat melakukan pekerjaan. Bekerja dengan posisi janggal meningkatkan jumlah energi yang dibutuhkan untuk bekerja. Posisi janggal menyebabkan kondisi dimana perpindahan tenaga dari otot ke jaringan rangka tidak efisien sehingga mudah menimbulkan lelah. Termasuk ke dalam postur janggal adalah pengulangan atau waktu lama dalam posisi menggapai, berputar (twisting), memiringkan badan, berlutut, jongkok, memegang dalam kondisi statis, dan menjepit dengan tangan. Postur ini melibatkan beberapa area tubuh seperti bahu, punggung dan lutut, karena bagian inilah yang paling sering mengalami cidera (Straker, 2000).

Keluhan muskuloskeletal berisiko dialami oleh pekerja bagian welding. Posisi postur tubuh pekerja selama proses pengelasan merupakan posisi postur tubuh yang berpotensi menyebabkan munculnya keluhan rasa nyeri di beberapa segmen tubuh operator. Hal ini dapat memengaruhi kinerja operator sehingga memungkinkan terjadinya kelainan bentuk tulang dan dapat berpengaruh pada produktivitas industri itu sendiri. Postur kerja yang tidak alami misalnya postur kerja yang selalu berdiri, jongkok, membungkuk dalam waktu yang lama dapat menyebabkan ketidaknyamanan dan nyeri pada salah satu anggota tubuh. Salah satu cara menganalisis postur tubuh tenaga kerja dilakukan dengan metode Ovako Work Analysis System (OWAS) yaitu metode untuk menilai postur tubuh saat bekerja yang berkaitan dengan bagian tubuh punggung, lengan, kaki, dan beban berat yang diangkat.

Pekerjaan-pekerjaan dan postur kerja yang statis sangat berpotensi mempercepat timbulnya kelelahan dan nyeri pada otot-otot yang terlibat. Jika kondisi seperti ini berlangsung setiap hari dan dalam waktu yang lama (kronis) bisa menimbulkan sakit permanen dan kerusakan pada otot, sendi, tendon, ligamen dan jaringan-jaringan lain. Selain itu, bekerja dengan rasa sakit dapat mengurangi produktivitas serta efisiensi kerja dan apabila bekerja dengan kesakitan ini diteruskan maka akan berakibat pada kecacatan yang akhirnya menghilangkan pekerjaan bagi pekerjanya. Terdapat lebih dari sepertiga dari seluruh waktu kerja yang hilang (lost time injuries) karena hal ini (Aprilia, 2009).

Studi tentang musculoskeletal disorders (MSDs) pada berbagai jenis industri telah banyak dilakukan dan hasil studi menunjukkan bahwa bagian otot yang sering dikeluhkan adalah otot rangka (skeletal) yang meliputi otot leher, bahu, lengan, tangan, jari, punggung, pinggang dan otot-otot bagian bawah (Tarwaka, 2010).

Data dari The Bureau of Labour Statistics (BLS), U.S Department of Labour yang dipublikasikan pada tanggal 9 November 2011 menunjukkan tingkat kejadian kasus keluhan muskuloskeletal yang mengakibatkan pekerja harus diistirahatkan meningkat 4\%, yaitu 34 kasus per 10.000 tenaga kerja penuh waktu. Tingkat kejadian MSDs untuk perawat, mantri dan pembantu meningkat $10 \%$ dari 249 kasus. Kasus MSDs pada pekerjaan tersebut juga meningkat sebesar 7\%. Sedangkan tingkat MSDs untuk buruh barang, perusahaan saham dan 
perusahaan bahan penggerak tidak mengalami perubahan signifikan pada jumlah kasus MSDs mereka.

Dari hasil penelitian Amalia (2011), mengenai hubungan kapasitas, beban dan postur kerja dengan keluhan otot rangka pada pekerja wanita bagian penjemuran di industri pembuatan genteng diperoleh bahwa ada hubungan yang signifikan antara umur $(\mathrm{p}=0,000$ dan $\mathrm{p}=0,003)$, masa kerja $(\mathrm{p}=0,005$ dan $\mathrm{p}=0,046$, dan postur kerja yaitu postur menjemur $(\mathrm{p}=0,000$ dan $\mathrm{p}=0,003)$ serta postur mengangkut $(\mathrm{p}=0,001$ dan $\mathrm{p}=0,007)$ dengan keluhan otot rangka segmen punggung dan lengan.

Penelitian Wijaya (2008) mengenai analisis postur kerja pada industri pembuatan tahu dengan menggunakan metode OWAS yang merupakan suatu metode untuk menilai postur tubuh saat bekerja. Metode ini menilai postur tubuh saat bekerja yang berkaitan dengan bagian tubuh punggung, lengan, kaki, dan beban berat yang diangkat. Masing-masing bagian memiliki klasifikasi sendiri-sendiri. Metode ini cepat dalam mengidentifikasi postur kerja yang berisiko menimbulkan keluhan musculoskeletal. Hasil penelitian Wijaya tersebut, terdapat 8 postur kerja masuk kategori risiko 4 yang berarti posisi kerja dengan efek sangat berbahaya pada sistem musculoskeletal, perlu perbaikan saat ini juga. Salah satu postur kerja pada kategori 4 berkode 4151 yang artinya punggung bungkuk ke depan dan menyamping, kedua lengan di bawah bahu, berdiri bertumpu pada satu kaki dengan lutut ditekuk, dan berat beban yang dibawa kurang atau sama dengan $10 \mathrm{~kg}$.

Penerapan dari metode ini dapat memberikan suatu hasil yang baik, yang dapat meningkatkan kenyamanan kerja, sebagai peningkatan produksi, setelah dilakukannya perbaikan sikap kerja. Sampai saat ini, metode ini telah diterapkan secara luas di berbagai sektor industri.

Penelitian Pangaribuan (2009) dengan menggunakan metode RULA yang merupakan suatu metode dengan menggunakan target postur tubuh untuk mengestimasi terjadinya risiko gangguan otot skeletal, khususnya pada anggota tubuh dari perut hingga leher atau anggota badan bagian atas. Dari hasil penelitian tersebut didapatkan hasil bahwa postur kerja yang memiliki level risiko tertinggi mengalami keluhan muskuloskeletal adalah postur kerja jongkok dan berdiri dengan tangan terentang ke atas serta kaki berjinjit. Postur kerja ini harus diperbaiki sekarang juga. Selain itu, postur kerja bungkuk dan berdiri dengan tangan terentang ke atas memiliki risiko sedang mengalami keluhan muskuloskeletal dan harus diperbaiki dalam waktu dekat. Sedangkan postur kerja berdiri berada pada level risiko yang kecil mengalami keluhan muskuloskeletal, tetapi juga perlu dilakukan tindakan perbaikan beberapa waktu ke depan.

Pengembangan penelitian ini dari penelitian sebelumnya adalah penelitian ini selain menganalisis postur kerja penelitian ini juga mengidentifikasi mengenai gambaran faktor individu yang meliputi umur, masa kerja, kebiasaan merokok, ukuran tubuh (antropometri) serta gambaran keluhan muskuloskeletal yang dialami oleh pekerja.

Dari beberapa uraian di atas jelas bahwa penerapan prinsip-prinsip ergonomi sangat dibutuhkan dalam melakukan pekerjaan yang sifatnya menggunakan kemampuan otot, karena beberapa masalah ergonomi (dalam hal ini cidera pada sistem muskuloskeletal) di atas tidak perlu terjadi apabila sikap kerja dan kondisi kerja baik, serta lingkungan pendukung yang baik seperti tekanan, getaran, mikrolimat, umur, jenis kelamin, kebiasaan merokok, kesegaran jasmani, kekuatan fisik serta ukuran tubuh (Tarwaka, 2004).

PT. ALSTOM Power Energy Systems Indonesia adalah sebuah perusahaan industri berteknologi tinggi yang merupakan pemain besar dalam pasar untuk sistem, peralatan dan jasa-jasa pada pembangkitan listrik. PT. ALSTOM Power Energy Systems Indonesia merupakan perusahaan multinational yang bergerak di bidang pembangkit tenaga listrik khususnya pembangkit listrik tenaga uap (PLTU). Tenaga kerja welding sangat dibutuhkan dalam industri pembuatan steam boiler di PT. ALSTOM Power Energy Systems Indonesia. Peran tenaga kerja bagian welding di industri ini yaitu untuk menggabungkan pipa baja sehingga terbentuk ikatan yang permanen.

Tenaga kerja bagian welding di area workshop Bay 4.2 PT. ALSTOM Power Energy Systems Indonesia ketika bekerja dapat berisiko mengalami keluhan muskuloskeletal. Postur kerja yang tidak ergonomis, tenaga yang berlebihan dan pengulangan tenaga kerja dapat meningkatkan timbulnya keluhan muskuloskeletal (Peter, 2000). Hal tersebut juga dapat dipengaruhi karena tenaga kerja bagian welding ketika bekerja salah satu posisinya dengan berlutut dan membungkuk.

Ditambah lagi tenaga kerja bagian welding atau bisa disebut pengelas merupakan tenaga kerja yang dituntut sehat dari segi fisiknya juga harus memiliki skill atau keterampilan mengelas yang baik. Dua 
hal ini menjadi penting dan saling mendukung, karena pada praktiknya keterampilan mengelas saja tidak cukup, kalo tidak didukung fisik yang prima, karena pekerjaan seorang pengelas memang cukup menguras tenaga. Pekerjaan yang paling sering membutuhkan tenaga ekstra adalah pada posisi-posisi sulit saat pengelasan harus dilakukan, misalnya pada posisi di ketinggian, pada posisi yang sempit dan lain-lain (Amalia, 2009).

Postur kerja merupakan titik penentu dalam analisa keefektifan tenaga kerja welding ketika mengelas pipa baja. Apabila postur kerja yang dilakukan sudah baik dan ergonomis maka dipastikan hasil yang diperoleh akan baik. Akan tetapi bila postur kerja tidak ergonomis maka akan menyebabkan kelelahan dan timbul keluhan muskuloskeletal. Hal ini dapat memengaruhi kinerja operator sehingga memungkinkan terjadinya kelainan bentuk tulang dan dapat berpengaruh pada produktivitas industri itu sendiri. Postur kerja yang tidak alami misalnya postur kerja yang selalu berdiri, jongkok, membungkuk dalam waktu yang lama dapat menyebabkan ketidaknyamanan dan nyeri pada salah satu anggota tubuh.

Penelitian ini hanya akan membahas mengenai postur kerja dan risiko terjadinya keluhan muskuloskeletal pada tenaga kerja welding di area workshop Bay 4.2 PT. ALSTOM Power Energy Systems Indonesia. Di dalam penelitian ini dilakukan observasi pada responden meliputi gerakan seluruh tubuh, perubahan postur tubuh saat bekerja serta pengukurannya dengan menggunakan metode OWAS. Kemudian untuk menghindari penafsiran yang tidak diinginkan peneliti membatasi permasalahan dengan hal yang berkaitan terhadap keluhan muskuloskeletal mengenai faktor pekerjaan yaitu postur kerja, faktor individu meliputi umur, masa kerja, kebiasaan merokok, dan ukuran tubuh (antropometri). Untuk menghindari terjadinya bias, responden yang memiliki riwayat penyakit rematik, asam urat maupun diabetes tidak akan dimasukkan ke dalam penelitian.

\section{METODE}

Merupakan penelitian observasional, karena fakta/data yang diperoleh melalui pengamatan dan tidak diberi perlakuan. Ditinjau dari segi waktunya penelitian dilakukan secara cross sectional, karena variabel yang termasuk faktor risiko dan variabel yang termasuk dampak diobservasi sekaligus dalam sekuen waktu yang sama. Jika ditinjau dari segi tempatnya penelitian ini termasuk penelitian lapangan. Berdasarkan sifatnya, merupakan penelitian deskriptif yaitu suatu metode penelitian yang dilakukan dengan tujuan untuk memberikan gambaran tentang suatu keadaan secara obyektif.

Populasi penelitian ini adalah keseluruhan dari subyek penelitian atau obyek yang akan diteliti. Populasi penelitian ini adalah tenaga kerja welding di area workshop Bay 4.2 PT. ALSTOM Power Energy Systems Indonesia yang berjumlah 13 orang dan waktu penelitian yaitu bulan Mei 2013.

Variabel yang akan diteliti postur kerja yaitu faktor individu diantaranya adalah umur, massa kerja, kebiasaan merokok dan antropometri. Variabel yang kedua posisi kerja yang dilakukan saat bekerja. Variabel yang ketiga keluhan musculoskeletal mengenai rasa sakit atau tidak enak pada otot rangka (skeletal) yang meliputi otot leher, bahu, tangan, lengan, jari, punggung, pinggang dan otot-otot bagian bawah yang dirasakan oleh pekerja sebelum, selama dan sesudah bekerja.

Teknik analisis data dengan menggunakan Pengumpulan data primer pada penelitian ini menggunakan teknik kuesioner, wawancara dan observasi kepada pekerja welding di area workshop Bay 4.2 sebagai responden yang berisi mengenai umur, masa kerja, kebiasaan merokok, ukuran tubuh (antropometri), postur tubuh saat bekerja, dan keluhan muskuloskeletal. Data sekunder diperoleh dari data bagian Keselamatan dan Kesehatan kerja PT. ALSTOM Power Energy Systems Indonesia. Data dan informasi yang telah diperoleh dari kuesioner, wawancara, observasi dan data hasil pengukuran kemudian dianalisis dengan tabel, dan narasi secara deskriptif yaitu dengan menggambarkan keadaan yang sebenarnya dari komunitas yang diteliti.

\section{HASIL}

\section{Gambaran Umum Perusahaan}

Pada awal berdirinya, perusahaan ini bernama PT. Sistem Energi Indonesia yang kemudian pada periode 1986-2001 perusahaan mengalami perubahan nama sebanyak 4 kali. Perubahan nama tersebut dikarenakan adanya perubahan kepemilikan perusahaan yang pada akhirnya resmi menjadi milik Perancis. Seiring berjalannya waktu, PT. Penataran Angkatan Laut (PAL) Indonesia dan PT. Barata Indonesia menggabungkan sahamnya dengan perusahaan pembuat steam boiler dengan bahan baku baja dengan kapasitas produksi $600.000 \mathrm{Mhrs/}$ 
tahun ini. Berikut rincian jumlah kepemilikan saham: PT. ALSTOM Power Energy System Indonesia $86,76 \%$, PT. PAL 12,63\%, PT. Barata Jaya $0,70 \%$. PT. ALSTOM Power Energy System Indonesia didirikan pada area seluas $49.654 \mathrm{~m}^{2}(4,97$ Ha). Umur responden berkisar antara 21-51 tahun yang kemudian dikelompokkan berdasarkan kategori umur. Setelah dikelompokkan maka diperoleh distribusi umur pekerja di Area Workshop Bay 4.2 PT. ALSTOM Power Energy System Indonesia, Mei 2013.

PT. ALSTOM Power Energy System Indonesia berlokasi di areal basis militer TNI-AL Kelurahan Ujung, Kecamatan Semampir, Surabaya Utara dengan alamat lengkap Jl. Panti Mulia Baru, Ujung, Surabaya. Dengan memilki beberapa kantor cabang yang terletak di Sengkang, Paiton, Medan, dan Jakarta, memungkinkan penyebaran pelayanan dengan cepat ke seluruh area kepulauan. Pelayanan yang dilakukan yaitu mulai dari pengepakan hingga perakitan boiler dan Heat Recovery Steam Generator (HRSG) dengan komponennya seperti waterwalls, superheater, pesawat pemanas ulang, alat pemanas udara, ecominizer, dan headers. Selain itu PT. ALSTOM Power Energy System Indonesia juga bertanggung jawab penuh atas pengoperasian system sepanjang masa kerja instalasi.

PT. ALSTOM Power Energy System Indonesia didirikan pada area seluas $49.654 \mathrm{~m}^{2}(4,97 \mathrm{Ha})$. Dengan status lahan adalah sewa jangka panjang (25 tahun) oleh PT. PAL dari TNI-AL (charter of Cooperation Between PT. PAL and the Indonesian Navy dated 27 juli 1995) dan hak pakai oleh PT. ALSTOM Power Energy System Indonesia dimana PT. PAL sebagai stakeholder PT. ALSTOM Power Energy System Indonesia. Area PT. ALSTOM Power Energy System Indonesia terbagi atas Area perkantoran: $5.004 \mathrm{~m}^{2}(0,5 \mathrm{Ha})$ dan Area proses industri: $44.650 \mathrm{~m}^{2}$ (4,447 Ha).

Proses produksi di PT. ALSTOM Power Energy System Indonesia diawali dengan mengolah bahan baku menjadi produk jadi. Berikut merupakan tahapan proses produksi yang dilakukan melalui proses mekanis yaitu proses pemotongan, pembentukan perangkaian, proses optimasi (penyempurnaan).

Bahan baku seperti tubes dipotong sesuai ukuran yang direncanakan sebelum dilakukan blasting, kemudian dirangkai sesuai dengan ukuran yang telah dirancang. Setiap tube maupun plate sebelum dirangkai, disempurnakan terlebih dahulu, baik dalam hal kehalusan permukaan maupun pelapisan dengan bahan tahan korosif dan tahan tekanan tinggi. Selain tes tersebut, juga dilakukan tes terhadap kesempurnaan penyambungan (las) dengan mengisi rangkaian dengan air yang telah diberi bahan kimia, bahan anti korosif, maupun anti jamur. Setelah digunakan dalam proses produksi, larutan bahan kimia ini menjadi limbah cair dengan volume maksimum sekitar $45 \mathrm{~m}^{3} /$ bulan. Rangkaian yang telah sempurna diberi kelengkapan seperti valve, pompa dan lainnya sesuai kebutuhan sehingga diperoleh produk akhir sesuai dengan spesifikasi yang diminta oleh konsumen. Setiap boiler memiliki desain yang berbeda-beda, dikarenakan adanya penyesuaian terhadap permintaan/order. Boiler merupakan gabungan panel-panel yang terdiri dari plat dan pipa, yang membedakan dengan bagian boiler hanyalah bentuk, ukuran, jenis bahan dan ada tidaknya tekanan gas dalam pipa. Proses produksi setiap komponen tersebut dapat dilihat bahwa proses produksi primer yang meliputi kegiatan dasar sebagai berikut Pembersihan material: pembersihan material dari kerak karena material datang dalam bentuk kasar dan kadang masih perlu dihaluskan terlebih dahulu agar bentuknya rata sebelum memasuki welding machine, rolling: rolling merupakan proses melenturkan material setelah diproses atau sebelum diproses. Hal ini di lakukan karena material menggelembung setelah melalui welding machine yang panas, marking: proses menandai material secara manual, misal garis yang akan dipotong, dilas atau dilubangi, cutting: proses pemotongan besi atau plat sesuai ukuran yang diinginkan. Proses pemotongan dapat dilakukan menggunakan mesin cutting manual/cutting CNC, bending: merupakan proses membengkokkan pipa besi sesuai bentuk yang diinginkan. Adapula beberapa produksi yang memerlukan proses bending sesudah di las, sehingga ukuran benda kerja menjadi cukup besar, welding: merupakan proses pengelasan sesuai bentuk yang diinginkan, baik untuk assembly antara pipa dengan plat atau pipa dan nozzle, Post Welding Heat Treatment (PWHT): proses pendinginan kembali material atau benda kerja sesudah dipanaskan, misal setelah dibending agar bentuk benda menjadi lebih halus, drilling: proses mengebor atau melubangi benda kerja, baik pipa atau plat. Proses tersebut bertujuan untuk melubangi pipa yang akan disambung dengan nozzle atau material lain dan melubangi pipa untuk menjaga agar udara panas yang tersimpan di dalam pipa dapat keluar dan tidak mengurangi kekuatan dari material, scarling: merupakan proses khusus untuk membuat 
superheater, air heater dan sebagainya. Bentuk yang muncul seperti adanya gerigi pada diameter yang diproses, painting: proses pengecatan benda kerja akhir sesuai yang dibutuhkan konsumen.

\section{Faktor Individu Pekerja Welding di Area Workshop Bay 4.2 PT. ALSTOM Power Energy System Indonesia}

Faktor individu pekerja welding di area workshop Bay 4.2 yang diteliti meliputi umur, masa kerja, kebiasaan merokok, dan ukuran tubuh (antropometri) dijelaskan dalam Tabel 1.

Dari tabel 1 dapat diketahui bahwa sebagian besar pekerja berumur 25-35 tahun, yaitu sebanyak 6 orang dari 13 total pekerja atau sebesar $46,15 \%$.

Dari tabel 2 dapat diketahui bahwa sebagian besar pekerja berumur 25-35 tahun, yaitu sebanyak 6 orang dari 13 total pekerja atau sebesar $46,15 \%$.

Dari Tabel 3 dapat diketahui bahwa pekerja yang memiliki kebiasaan merokok sebanyak 7 pekerja $(53,85 \%)$, sedangkan 6 pekerja $(46,15 \%)$ tidak merokok.

Dari tabel di atas dapat diketahui bahwa sebagian besar sebanyak 8 orang pekerja dari 13 total pekerja memiliki BMI kategori overweight pre-obese yaitu sebesar $61,54 \%$. Dari hasil penelitian tidak terdapat pekerja yang mempunyai BMI kategori

Tabel 1. Hasil Pengukuran Faktor Individu Berdasarkan Umur

\begin{tabular}{ccc}
\hline \multirow{2}{*}{ Umur } & \multicolumn{2}{c}{ Jumlah } \\
\cline { 2 - 3 } & $\mathbf{N}$ & $\mathbf{\%}$ \\
\hline$<25$ tahun & 1 & 7,70 \\
$25-35$ tahun & 6 & 46,15 \\
$35-45$ tahun & 4 & 30,77 \\
$>45$ tahun & 2 & 15,38 \\
\hline Total & 13 & 100,00 \\
\hline
\end{tabular}

Tabel 2. Hasil Pengukuran Faktor Individu Berdasarkan Masa Kerja

\begin{tabular}{ccc}
\hline \multirow{2}{*}{ Masa Kerja } & \multicolumn{2}{c}{ Jumlah } \\
\cline { 2 - 3 } & $\mathbf{N}$ & $\mathbf{\%}$ \\
\hline$<5$ tahun & 2 & 15,39 \\
$5-10$ tahun & 5 & 38,46 \\
$>10$ tahun & 6 & 46,15 \\
\hline Total & 13 & 100,00 \\
\hline
\end{tabular}

Tabel 3. Hasil Pengukuran Faktor Individu Berdasarkan Kebiasaan Merokok

\begin{tabular}{ccc}
\hline \multirow{2}{*}{ Kebiasaan Merokok } & \multicolumn{2}{c}{ Jumlah } \\
\cline { 2 - 3 } & N & \% \\
\hline Ya & 7 & 53,85 \\
Tidak & 6 & 46,15 \\
\hline Total & 13 & 100,00 \\
\hline
\end{tabular}

Tabel 4. Hasil Pengukuran Faktor Individu Berdasarkan Ukuran Tubuh (Antropometri)

\begin{tabular}{ccc}
\hline \multirow{2}{*}{ Klasifikasi BMI } & \multicolumn{2}{c}{ Jumlah } \\
\cline { 2 - 3 } & $\mathbf{N}$ & $\mathbf{\%}$ \\
\hline Underweight & & \\
Moderate thinness & 1 & 7,69 \\
Normal & 4 & 30,77 \\
Overweight & & \\
Pre-obese & 8 & 61,54 \\
\hline Total & 13 & 100,0 \\
\hline
\end{tabular}

Tabel 5. Hasil Penilaian Postur Kerja

\begin{tabular}{cccc}
\hline Nama & $\begin{array}{c}\text { Kode } \\
\text { Postur }\end{array}$ & $\begin{array}{c}\text { Kategori } \\
\text { Risiko }\end{array}$ & $\begin{array}{c}\text { Frekuensi } \\
\text { Relatif (\%) }\end{array}$ \\
\hline AR & 2111 & 2 & $100 \%$ \\
& 2361 & 4 & $3 \%$ \\
AN & 1361 & 1 & $3 \%$ \\
& 1121 & 1 & $82 \%$ \\
FM & 2121 & 2 & $12 \%$ \\
& 2161 & 2 & $100 \%$ \\
HT & 1311 & 1 & $31 \%$ \\
& 4131 & 2 & $14 \%$ \\
& 4121 & 2 & $17 \%$ \\
HR & 2111 & 2 & $38 \%$ \\
MN & 2111 & 2 & $100 \%$ \\
KR & 2111 & 2 & $100 \%$ \\
YK & 2111 & 2 & $100 \%$ \\
YS & 2111 & 2 & $100 \%$ \\
NS & 1311 & 2 & $100 \%$ \\
& 1311 & 1 & $100 \%$ \\
IM & 2131 & 2 & $40 \%$ \\
IG & 2111 & 2 & $60 \%$ \\
SA & 2121 & 2 & $100 \%$ \\
& 2161 & 2 & $86 \%$ \\
\hline
\end{tabular}


underweight (severe thinness, mild thinness), Obese (obese class I, obese class II, obese class III).

Setelah dilakukan identifikasi dan penilaian postur kerja kemudian dilakukan pemilihan postur kerja berdasarkan posisi tubuh yang paling dominan dilihat dari frekuensi relatif. Hal ini dilakukan untuk mengetahui postur tubuh yang bagaimana yang paling dominan dan paling sering dilakukan ketika melakukan pekerjaan. Pemilihan postur kerja yang paling dominan digunakan untuk memilih postur kerja pada pekerja welding yang melakukan lebih dari satu postur kerja ketika dilakukan pengamatan.
Keluhan Muskuloskeletal pada Pekerja Welder di Area Workshop Bay 4.2 PT. ALSTOM Power Energy System Indonesia

Hasil pengukuran keluhan muskuloskeletal pada pekerja welding di area workshop Bay 4.2 PT. ALSTOM Power Energy System Indonesia dapat diketahui bahwa keluhan muskuloskeletal yang paling banyak dialami oleh pekerja welding adalah pada pinggang, yaitu sebanyak 12 dari 13 pekerja $(92,31 \%)$. Para pekerja yang mayoritas melakukan posisi membungkuk dan duduk ketika melakukan pekerjaan welding menyebabkan kebanyakan para

Tabel 6. Keluhan Musculoskeletal Disorders (MSDs)

\begin{tabular}{|c|c|c|c|c|c|c|}
\hline \multirow{3}{*}{ Otot skeletal } & \multicolumn{4}{|c|}{ Keluhan MSDs } & \multirow{2}{*}{\multicolumn{2}{|c|}{ Total }} \\
\hline & \multicolumn{2}{|c|}{ Ya } & \multicolumn{2}{|c|}{ Tidak } & & \\
\hline & $\mathbf{n}$ & $\%$ & $\mathbf{n}$ & $\%$ & $\mathbf{N}$ & $\%$ \\
\hline Leher bagian atas & 4 & 30,77 & 9 & 69,23 & 13 & 100,0 \\
\hline Leher bagian bawah & 8 & 61,54 & 5 & 38,46 & 13 & 100,0 \\
\hline Bahu Kiri & 3 & 23,08 & 10 & 76,92 & 13 & 100,0 \\
\hline Bahu kanan & 3 & 23,08 & 10 & 76,92 & 13 & 100,0 \\
\hline Lengan atas kiri & 6 & 46,15 & 7 & 53,85 & 13 & 100,0 \\
\hline Punggung & 4 & 30,77 & 9 & 69,23 & 13 & 100,0 \\
\hline Lengan atas kanan & 6 & 46,15 & 7 & 53,85 & 13 & 100,0 \\
\hline Pinggang & 1 & 7,69 & 12 & 92,31 & 13 & 100,0 \\
\hline Pinggul & 10 & 76,92 & 3 & 23,08 & 13 & 100,0 \\
\hline Pantat & 11 & 84,62 & 2 & 15,38 & 13 & 100,0 \\
\hline Siku kiri & 12 & 92,31 & 1 & 7,69 & 13 & 100,0 \\
\hline Siku kanan & 12 & 92,31 & 1 & 7,69 & 13 & 100,0 \\
\hline Lengan bawah kiri & 10 & 76,92 & 3 & 23,08 & 13 & 100,0 \\
\hline Lengan bawah kanan & 10 & 76,92 & 3 & 23,08 & 13 & 100,0 \\
\hline Pergelangan tangan kiri & 10 & 76,92 & 3 & 23,08 & 13 & 100,0 \\
\hline Pergelangan tangan kanan & 9 & 69,23 & 4 & 30,77 & 13 & 100,0 \\
\hline Tangan kiri & 9 & 69,23 & 4 & 30,77 & 13 & 100,0 \\
\hline Tangan kanan & 9 & 69,23 & 4 & 30,77 & 13 & 100,0 \\
\hline Paha kiri & 7 & 53,85 & 6 & 46,15 & 13 & 100,0 \\
\hline Paha kanan & 8 & 61,54 & 5 & 38,46 & 13 & 100,0 \\
\hline Lutut kiri & 8 & 61,54 & 5 & 38,46 & 13 & 100,0 \\
\hline Lutut kanan & 9 & 69,23 & 4 & 30,77 & 13 & 100,0 \\
\hline Betis kiri & 3 & 23,08 & 10 & 76,92 & 13 & 100,0 \\
\hline Betis kanan & 3 & 23,08 & 10 & 76,92 & 13 & 100,0 \\
\hline Pergelangan kaki kiri & 7 & 53,85 & 6 & 46,15 & 13 & 100,0 \\
\hline Pergelangan kaki kanan & 7 & 53,85 & 6 & 46,15 & 13 & 100,0 \\
\hline Kaki kiri & 9 & 69,23 & 4 & 30,77 & 13 & 100,0 \\
\hline Kaki kanan & 9 & 69,23 & 4 & 30,77 & 13 & 100,0 \\
\hline
\end{tabular}


pekerja mengalami keluhan muskuloskeletal pada bagian pinggang.

\section{PEMBAHASAN}

\section{Kejadian Musculoskeletal Disorders (MSDs) Dilihat dari Umur}

Hasil penelitian menunjukkan bahwa umur pekerja berkisar antara 21-51 tahun. Sebagian besar pekerja berusia 25-35 tahun, yaitu sebanyak 6 orang dari 13 total pekerja atau sebesar $46,15 \%$. Tarwaka (2010) menyatakan bahwa pada umumnya keluhan otot skeletal mulai dirasakan pada usia kerja, yaitu usia 25-65 tahun. Keluhan pertama biasanya dirasakan pada umur 35 tahun dan tingkat keluhan akan terus meningkat sejalan dengan bertambahnya umur. Hal ini terjadi karena pada umur setengah baya, kekuatan dan ketahanan otot mulai menurun sehingga risiko terjadinya keluhan otot meningkat

Sebagai contoh, Betti'e et al. (1989) telah melakukan studi tentang kekuatan statis otot untuk pria dan wanita dengan usia antara 20 sampai dengan di atas 60 tahun. Penelitian menunjukkan bahwa kekuatan otot maksimal terjadi pada saat umur antara 20-29 tahun, selanjutnya terus terjadi penurunan sejalan dengan bertambahnya umur. Pada saat mencapai 60 tahun, rerata kekuatan otot menurun sampai $20 \%$. Pada saat kekuatan otot mulai menurun inilah maka risiko terjadinya keluhan otot semakin meningkat.

Berdasarkan hasil penelitian yang telah dibandingkan dengan Tarwaka (2010) dan beberapa ahli yang lain, sebagian besar pekerja yang berusia $<35$ tahun seharusnya memiliki risiko kecil atau bahkan tidak mengalami keluhan muskuloskeletal. Namun, setelah dilakukan penilaian keluhan muskuloskeletal didapatkan hasil bahwa semua pekerja welding di area workshop bay $4.2 \mathrm{PT}$. ALSTOM Power Energy Systems Indonesia dengan umur berapapun mengalami keluhan muskuloskeletal.

\section{Kejadian Musculoskeletal Disorders (MSDs) Dilihat dari Masa Kerja}

Hasil penelitian menunjukkan bahwa masa kerja pekerja berkisar selama 2-15 tahun. Sebagian besar pekerja bekerja selama $>10$ tahun, yaitu sebanyak 6 orang dari 13 orang pekerja atau sebesar $46,15 \%$.

Pekerja welding yang mempunyai masa kerja $<5$ tahun sebanyak 2 orang, untuk pekerja yang mempunyai masa kerja 5-10 tahun sebanyak 5 orang dan sebanyak 6 orang mempunyai masa kerja $>10$ tahun. Masa kerja dalam penelitian menyatakan berapa lama seseorang bekerja dan masa kerja dapat memberikan dampak positif dan negatif bagi pekerja tersebut. Dampak positifnya adalah pekerja yang sudah lama bekerja semakin berpengalaman untuk melaksanakan pekerjaannya dan mengetahui risiko bahaya yang akan diterima utamanya bahaya ergonomi, sedangkan dampak negatifnya pekerja merasa sudah ahli dalam melaksanakan pekerjaannya, namun secara tidak sadar pekerja tersebut dapat membahayakan dirinya sendiri maupun rekan kerjanya. Sehingga hal ini dapat mengakibatkan sebagian besar pekerja mengalami keluhan muskuloskeletal.

Tarwaka (2010) menyatakan bahwa penyakit MSDs ini merupakan penyakit kronis yang membutuhkan waktu lama untuk berkembang dan bermanifestasi. Jadi semakin lama bekerja semakin lama orang terpajan risiko untuk mengalami MSDs ini, maka semakin besar pula risiko untuk mengalami MSDs

Dari hasil penelitian yang telah dibandingkan dengan Tarwaka (2010) didapatkan seluruh pekerja dari masa kerja berapapun berisiko mengalami keluhan muskuloskeletal. Setelah dilakukan penilaian keluhan muskuloskeletal kepada pekerja welding di area workshop bay 4.2 PT. ALSTOM Power Energy Systems Indonesia didapatkan hasil bahwa seluruh pekerja mengalami keluhan muskuloskeletal.

\section{Kejadian Musculoskeletal Disorders (MSDs) Dilihat dari Kebiasaan Merokok}

Hasil penelitian menunjukkan bahwa sebanyak 7 dari 13 pekerja atau sebesar 53,85\% memiliki kebiasaan merokok.

Menurut Tarwaka (2010) pengaruh kebiasaan merokok terhadap risiko keluhan otot juga masih diperdebatkan oleh para ahli, namun demikian beberapa penelitian telah membuktikan bahwa meningkatnya keluhan otot sangat erat hubungannya dengan lama dan tingkat kebiasaan merokok. Semakin lama dan semakin tinggi frekuensi merokok, semakin tinggi pula tingkat keluhan otot yang dirasakan.

Boshizuen, et al (1993) dalam Tarwaka (2010) menemukan hubungan yang signifikan antara kebiasaan merokok dengan keluhan otot pinggang, khususnya untuk pekerjaan yang memerlukan pengerahan otot. Hal ini sebenarnya terkait erat dengan kondisi kesegaran tubuh seseorang. 
Kebiasaan merokok akan dapat menurunkan kapasitas paru-paru, sehingga kemampuan untuk mengonsumsi oksigen menurun dan sebagai akibatnya, tingkat kesegaran tubuh juga menurun. Apabila yang bersangkutan harus melakukan tugas yang menuntut pengerahan tenaga, maka akan mudah lelah karena kandungan oksigen dalam darah rendah, pembakaran karbohidrat terhambat, terjadi tumpukan asam laktat dan akhirnya timbul rasa nyeri otot.

Hasil penelitian diketahui 7 orang dari 13 orang pekerja memiliki kebiasaan merokok yang berarti semakin besar risiko pekerja mengalami keluhan muskuloskeletal. Hal ini perlu menjadi masukan untuk perusahaan agar memperhatikan kesehatan para pekerjanya termasuk kebiasaan merokok. Untuk itu perusahaan perlu memberikan penyuluhan atau safety talk kepada pekerja sebelum mereka bekerja mengenai risiko merokok terhadap kesehatan dan produktivitas kerja. Bila perlu perusahaan mempersempit zona merokok di daerah perusahaan. Hal ini agar para pekerja dapat mengurangi atau menghentikan kebiasaan merokok mereka.

\section{Kejadian Musculoskeletal Disorders (MSDs) Dilihat dari Ukuran Tubuh (Antropometri)}

Hasil penelitian dan perhitungan dari BMI menunjukkan 8 orang dari 13 orang pekerja memiliki BMI dalam kategori Overweight Preobese, yaitu sebesar $61,54 \%$. Sebanyak $30,77 \%$ pekerja dikategorikan dalam berat badan normal dan $7,69 \%$ termasuk dalam kategori moderate thinness.

Tarwaka (2010) menyatakan pengaruh yang relatif kecil antara berat badan, tinggi badan, dan massa tubuh dengan kejadian keluhan muskuloskeletal. Tubuh yang tinggi sering menderita keluhan sakit punggung tapi tubuh yang tinggi tidak mempunyai pengaruh terhadap keluhan leher, bahu, dan pergelangan tangan. Tubuh yang tinggi mempunyai bentuk tulang yang langsing sehingga secara biomekanik rentan terhadap beban tekan dan rentan terhadap tekukan sehingga tinggi badan yang tinggi memiliki risiko lebih tinggi terhadap keluhan muskuloskeletal. Pasien yang gemuk (obesitas dengan indeks massa tubuh $>29$ ) mempunyai risiko 2,5 lebih tinggi risiko muskuloskeletal jika dibandingkan dengan pasien yang kurus (indeks massa tubuh $<20$ wanita yang gemuk mempunyai risiko dua kali lipat terkena muskuloskeletal jika dibandingkan dengan wanita kurus.

Hasil penelitian diketahui sebanyak sebesar 8 dari 13 pekerja tergolong dalam BMI kategori
Overweight Pre-obese yang berarti semakin besar risiko pekerja mengalami keluhan muskuloskeletal. Hal ini perlu menjadi masukan untuk perusahaan agar memperhatikan kesehatan para pekerjanya terutama yang memiliki BMI kategori Overweight Pre-obese. Untuk itu perusahaan perlu mengadakan olah raga yang diikuti oleh para pekerja setiap seminggu sekali.

\section{Kejadian Musculoskeletal Disorders (MSDs) Dilihat dari Postur Kerja}

Analisa postur kerja diperoleh dengan menggunakan OWAS yaitu metode yang digunakan untuk menilai postur tubuh pada saat bekerja yang meliputi bagian punggung, lengan, kaki dan berat beban. Metode ini menerjemahkan postur kerja dari hasil pengamatan yaitu berupa foto sesuai dengan postur kerja menurut kode empat digit. Kode tersebut meliputi postur tubuh bagian punggung, lengan, kaki dan berat beban. Setelah dilakukan pemberian kode untuk setiap posisi dan pembebanan menghitung setiap kode posisi, kategori risiko mana dia berasal untuk mengidentifikasi posisi kritis atau yang lebih tinggi tingkat risikonya bagi pekerja. Selanjutnya menghitung frekuensi relatif dari masing-masing posisi punggung, lengan dan kaki. Penentuan hasil identifikasi pekerjaan pada posisi kritis, tergantung pada frekuensi relatif dari masing-masing posisi, kategori risiko didasarkan pada masing-masing posisi dari berbagai bagian tubuh (punggung, lengan, dan kaki). OWAS menyatakan frekuensi dan proporsi relatif dari waktu yang dihabiskan untuk postur spesifik dan penilaian dengan skala empat level tingkat bahaya dari postur dengan tingkat prioritas untuk mengoreksi postur tersebut. Kombinasi postur yang diamati akan diklasifikasikan menurut tingkat bahayanya.

Hasil penelitian berdasarkan dari kombinasi posisi yang diamati dan posisi tubuh yang paling dominan didapatkan hasil bahwa terdapat 11 orang yang memiliki kategori risiko 2 (risiko sedang) dengan jumlah kode posisi sebanyak 3 yaitu kode posisi 2111, kode posisi 2161, kode posisi 2131. Sedangkan sebanyak 2 orang melakukan pekerjaan dengan postur kerja kategori risiko 1 (risiko rendah) dengan jumlah kode posisi sebanyak 2 yaitu kode posisi 1121 dan kode posisi 1311. Selain itu pekerja welding cenderung melaksanakan pekerjaan dengan postur kerja janggal seperti punggung yang membungkuk, posisi tangan terangkat atau di atas bahu, berlutut, berdiri dengan salah satu kaki ditekuk. 
Menurut Humantech (1995) menjelaskan bahwa salah satu faktor untuk terjadinya gangguan penyakit, atau cidera pada sistem muskuloskeletal adalah postur janggal.

Sikap kerja tidak alamiah atau postur kerja janggal adalah postur kerja yang dilakukan dengan posisi tubuh bergerak menjauhi posisi alamiah seperti punggung yang terlalu membungkuk, tangan dalam posisi terangkat, posisi jongkok, posisi badan memuntir, dan lainnya. Sikap kerja tidak alamiah/postur kerja janggal ini pada umumnya karena karakteristik tuntutan tugas, alat kerja dan stasiun kerja tidak sesuai dengan kemampuan dan keterbatasan pekerja Grandjean, 1993; Anis \& McConville, 1996; Waters \& Anderson, 1996 \& Manuaba, 2000 dalam Tarwaka (2010).

\section{Pembahasan Hasil Identifikasi dan Penilaian Postur Kerja Kategori Risiko 1 (Risiko Rendah)}

Hasil perhitungan postur kerja dengan metode OWAS kategori risiko rendah didapatkan kode postur 1121 (1 orang) dan 1311 (1 orang). Hasil perhitungan OWAS berdasarkan kode postur 1121 yaitu, posisi punggung lurus sehingga kode 1 diberikan untuk punggung. Posisi lengan di beri kode 1 karena kedua lengan berada di bawah bahu. Posisi kaki diberi kode 2 karena pekerjaan dilakukan sambil berdiri dengan kedua kaki lurus. Berat beban diberi kode 1 karena beban yang dibawa/diangkat $<10 \mathrm{~kg}$. Berdasarkan kombinasi setiap posisi tersebut, maka dapat disimpulkan bahwa posisi tubuh pekerja termasuk dalam kategori risiko 1 yang berarti posisi normal tanpa efek yang dapat mengganggu sistem muskuloskeletal (risiko rendah) sehingga tidak diperlukan tindakan perbaikan.

Hasil perhitungan OWAS berdasarkan kode postur 1311 yaitu, posisi punggung lurus sehingga kode 1 diberikan untuk punggung. Posisi lengan di beri kode 3 karena kedua lengan berada di atas bahu. Posisi kaki diberi kode 1 karena pekerjaan dilakukan sambil duduk. Berat beban diberi kode 1 karena beban yang di bawa/diangkat $<10 \mathrm{~kg}$. Berdasarkan kombinasi setiap posisi tersebut, maka dapat disimpulkan bahwa posisi tubuh pekerja termasuk dalam kategori risiko 1 yang berarti posisi normal tanpa efek yang dapat mengganggu sistem muskuloskeletal (risiko rendah) sehingga tidak diperlukan tindakan perbaikan.

\section{Kategori Risiko 2 (Risiko Sedang)}

Hasil perhitungan postur kerja dengan metode OWAS kategori risiko rendah didapatkan kode postur 2111 (8 orang), 2161 (2 orang) dan 2131 (1 orang). Hasil perhitungan OWAS berdasarkan kode postur 2111 yaitu, posisi punggung membungkuk sehingga kode 2 diberikan untuk punggung. Posisi lengan di beri kode 1 karena kedua lengan berada di bawah bahu. Posisi kaki diberi kode 1 karena pekerjaan dilakukan sambil duduk. Berat beban diberi kode 1 karena beban yang dibawa/diangkat $<10 \mathrm{~kg}$. Berdasarkan kombinasi setiap posisi tersebut, maka dapat disimpulkan bahwa posisi tubuh pekerja termasuk dalam kategori risiko 2 yang berarti posisi berpotensi menyebabkan kerusakan pada sistem muskuloskeletal (risiko sedang) sehingga tindakan perbaikan mungkin diperlukan.

Hasil perhitungan OWAS berdasarkan kode postur 2161 yaitu, posisi punggung membungkuk sehingga kode 2 diberikan untuk punggung. Posisi lengan diberi kode 1 karena kedua lengan berada di bawah bahu. Posisi kaki diberi kode 6 karena pekerjaan dilakukan sambil berlutut. Berat beban diberi kode 1 karena beban yang dibawa/diangkat $<10 \mathrm{~kg}$. Berdasarkan kombinasi setiap posisi tersebut, maka dapat disimpulkan bahwa posisi tubuh pekerja termasuk dalam kategori risiko 2 yang berarti posisi berpotensi menyebabkan kerusakan pada sistem muskuloskeletal (risiko sedang) sehingga tindakan perbaikan mungkin diperlukan.

Hasil perhitungan OWAS berdasarkan kode postur 2131 yaitu, posisi punggung membungkuk sehingga kode 2 diberikan untuk punggung. Posisi lengan diberi kode 1 karena kedua lengan berada di bawah bahu. Posisi kaki diberi kode 3 karena pekerjaan dilakukan sambil berdiri dengan salah satu kaki ditekuk. Berat beban diberi kode 1 karena beban yang dibawa/diangkat $<10 \mathrm{~kg}$. Berdasarkan kombinasi setiap posisi tersebut, maka dapat disimpulkan bahwa posisi tubuh pekerja termasuk dalam kategori risiko 2 yang berarti posisi berpotensi menyebabkan kerusakan pada sistem muskuloskeletal (risiko sedang) sehingga tindakan perbaikan mungkin diperlukan.

Menurut Humantech (1995) menjelaskan bahwa salah satu faktor risiko ergonomi yang dapat menyebabkan terjadinya gangguan penyakit, atau cidera pada sistem muskuloskeletal adalah postur janggal. Beberapa postur janggal yang 
mempunyai risiko terjadinya gangguan pada sistem muskuloskeletal yaitu punggung membungkuk (bent forward), yaitu punggung dan dada lebih condong ke depan membentuk sudut $\geq 20^{\circ}$ terhadap garis vertikal. Postur janggal lain yaitu pada kaki yaitu berlutut (kneeling), yaitu posisi tubuh dimana sendi menekuk, permukaan lutut menyentuh lantai dan berat tubuh bertumpu pada lutut dan jari-jari kaki. Postur janggal lain pada kaki yaitu berdiri pada satu kaki (stand on one leg), yaitu posisi tubuh ketika tubuh bertumpu pada satu kaki.

Dari hasil penelitian didapatkan hasil bahwa terdapat 2 orang pekerja welding yang mempunyai kategori risiko rendah dan sebanyak 11 orang mempunyai kategori risiko sedang. Meskipun dari hasil penelitian didapatkan bahwa terdapat 2 orang yang mempunyai kategori risiko rendah yang berarti tidak diperlukan tindakan perbaikan. Namun setelah dilakukan wawancara dengan pekerja welding didapatkan bahwa semua pekerja welding di area workshop bay 4.2 PT. ALSTOM Power Energy Systems Indonesia mengalami keluhan muskuloskeletal.

\section{Identifikasi Keluhan Muskuloskeletal Pekerja Welding di Area Workshop Bay 4.2 PT. Alstom Energy System Indonesia}

Berdasarkan hasil penelitian dari keluhan muskuloskeletal pekerja diketahui bahwa keseluruhan pekerja mengalami keluhan muskuloskeletal, sebagian besar pekerja mengalami keluhan pada bagian pinggang yaitu sebanyak 12 orang $(92,31 \%)$. Bagian otot skeletal yang banyak dikeluhkan berdasarkan pengakuan pekerja adalah pinggang $(92,31 \%)$, betis kiri $(76,92 \%)$, bahu kiri $(76,92)$, bahu kanan $(76,92)$, dan betis kanan (76,92).

Identifikasi keluhan muskuloskeletal pada pekerja menggunakan metode Nordic Body Map yaitu dengan menggunakan lembar kerja berupa peta tubuh dan mudah dipahami dengan langsung mewawancarai atau menanyakan kepada responden. Metode penilaian ini sangat subyektif artinya keberhasilan aplikasi metode ini sangat tergantung dari kondisi dan situasi yang dialami pekerja pada saat dilakukannya penilaian. Nordic Body Map meliputi 28 bagian otot skeletal pada kedua sisi tubuh kanan dan kiri. Dimulai dari anggota tubuh bagian atas yaitu otot leher sampai dengan bagian paling bawah yaitu otot kaki.

Peter (2000) menjelaskan terdapat faktor penyebab terjadinya keluhan sistem muskuloskeletal, yaitu peregangan otot yang berlebihan, aktivitas berulang, dan sikap kerja tidak alamiah. Aktivitas berulang, dan sikap kerja tidak alamiah dialami oleh pekerja welding dalam keseharian menjalankan pekerjaan. Aktivitas pekerja welding yang berisiko menimbulkan keluhan muskuloskeletal saat dilakukan penelitian adalah melakukan posisi berulang pada saat melakukan pengelasan. Sikap kerja tidak alamiah pekerja welding ketika bekerja yaitu postur kerja yang menjauhi posisi normal seperti posisi punggung yang membungkuk, bekerja dengan posisi berlutut, dan bekerja dengan posisi lengan berada di atas bahu.

Dilihat dari hasil penelitian, pekerjaan welding merupakan pekerjaan dimana dituntut bisa mengelas pada berbagai jenis posisi yang tidak jarang posisi tersebut dilakukan secara berulang dan tidak dengan postur kerja yang benar misalnya punggung membungkuk, berlutut, dan lengan berada di atas bahu. Maka responden dalam hal ini yaitu pekerja welding mempunyai risiko terkena keluhan muskuloskeletal.

\section{SIMPULAN}

Faktor individu yang mengalami keluhan muskuloskeletal pada responden mayoritas berusia 25-35 tahun, telah bekerja selama $>10$ tahun, memiliki kebiasaan merokok, dan memiliki BMI kategori overweight pre-obese.

Identifikasi dan penilaian postur kerja dari 13 orang pekerja welding diperoleh dua pekerja yang mempunyai kategori risiko 1 (risiko rendah), sebelas pekerja yang mempunyai kategori risiko 2 (risiko sedang). Sebanyak 92,31\% pekerja pernah mengalami keluhan muskuloskeletal dengan rasa sakit terbanyak pada otot skeletal pinggang.

Mengadakan penyuluhan atau safety talk tentang merokok bagi pekerja, sehingga bagi pekerja yang merokok dapat menghentikan atau mengurangi kebiasaan merokok. Pengaturan berat badan untuk pekerja yang memiliki kategori overweight pre-obese dengan melakukan olah raga setiap seminggu sekali sehingga tercapai berat badan yang normal (BMI = 18,5-24,99). Penyediaan peralatan dan stasiun kerja yang dapat diatur sesuai kebutuhan (adjustable) sehingga memperkecil jarak antara pekerja dengan obyek kerja. Jika tidak bisa, dapat juga menyediakan alat bantu yang dapat mengurangi postur janggal pekerja selama bekerja seperti menyediakan bangku kecil agar pekerja tidak berlutut atau membungkuk. 
Di bawah ini contoh model bangku kecil yang disarankan.???

\section{DAFTAR PUSTAKA}

Amalia. 2009. Welder Sebagai Profesi. http:// gowelding.blogspot.com/2009/12/lagi-keeping. html. (Sitasi 5 November 2012).

Amalia, R.U. 2011. Hubungan Kapasitas, Beban dan Postur Kerja dengan Keluhan Otot Rangka pada Pekerja Wanita Bagian Penjemuran di Sentra Industri Pembuatan Genteng. Skripsi. Semarang: Fakultas Kesehatan Masyarakat Universitas Diponegoro.

Aprilia, M. 2009. Tinjauan Faktor Risiko Ergonomi Terkait Keluhan Musculoskeletal Disorders (MSDs) pada Pekerja Konstruksi PT. Waskita Karya di Proyek Fasilitas Rekreasi dan Olahraga Boker Ciracas. Skripsi. Surabaya: Fakultas Kesehatan Masyarakat Universitas Indonesia.

Betti'e, M.C., Bigos, L.D., Fisher, T.H. 1989. Isometric Lifting Strength as a Predictor of Industrial Back Pain Report. Spine 14 (8): 851-856.

Humantech. 1995. Applied Ergonomics Training Manual $2^{\text {nd }}$. Australia: Barkeley Vale.
Pangaribuan, D.M. 2009. Analisa Postur Kerja Dengan Metode RULA pada Pegawai Bagian Pelayanan Perpustakaan USU Medan. Skripsi. Medan: Universitas Sumatera Utara.

Peter, Vi. 2000. Musculoskeletal Disorders. http:// www.csao.org/uploadfiles/magazine/vol.11no3/ musculo.html. (Sitasi 12 Juni 2013).

Sedarmayanti. 1996. Ergonomi untuk Produktivitas Kerja. http://www.belbuk.com/tata-kerja-danproduktivitas-kerja-p-4760.html. (Sitasi 29 Oktober 2012).

Soedirman. 1989. Penyakit Akibat Kerja dan Penyakit yang Berhubungan dengan Pekerjaan. Jakarta: Universitas Indonesia.

Straker, L.M. 2000. An Overview of Manual Handling Injury Statistic in Ergonomic Methods. USA: CRC Press.

Tarwaka. 2010. Ergonomi Industri Dasar-Dasar Pengetahuan Ergonomi dan Aplikasi di Tempat Kerja. Solo: Harapan Press.

Tarwaka. 2004. Ergonomi untuk Keselamatan, Kesehatan Kerja, dan Produktivitas. Surakarta: UNIBA Press.

Wijaya, A. 2008. Analisa Postur Kerja dan Perancangan Alat Bantu untuk Aktivitas Manual Material Handling Industri Kecil. Skripsi. Surakarta: Universitas Muhammadiyah. 